Spect al variat $i$ on of veget at $i$ ve areas in l eaf- of $f$ season observed by hyper spectral data

\begin{tabular}{|l|l|}
\hline 著者 & $\begin{array}{l}\text { Lee Kyu- Sung, Ki m Sun- Hwa, Ma J eong- Ri m Kook } \\
\text { Mn- Jung, I nha Jung- I I Shi n, Eo Yang- Dam Lee } \\
\text { Yong- Wbong }\end{array}$ \\
\hline j our nal or \\
publ i cat i on ti tl e & $\begin{array}{l}\text { Envi r onment al Noni t or i ng I n East Asi a ; Rentt e } \\
\text { Sensi ng and For est s }\end{array}$ \\
\hline page r ange & $71-74$ \\
\hline year & $2005-01-01$ \\
\hline URL & ht t p: //hdl . handl e. net /2297/6327 \\
\hline
\end{tabular}




\section{Spectal Variation of Vegetative Areas in Leaf-off Season Observed by Hyperspectral Data}

\author{
Kyu-Sung Lee, Sun-Hwa Kim, Jeong-Rim Ma, \\ Min-Jung Kook, Jung-Il Shin \\ Inha University, Dept. of Geoinformatic Engr. \\ Image Information Research Center \\ Yonghyun-dong, Nam-ku, Incheon 402-751, KOREA
}

\begin{abstract}
Due to the phenological variation of vegetation growth in temperate region, it is often difficult to accurately assess the surface conditions on agricultural croplands, grasslands, and disturbed forests by current multi-spectral remote sensor data. In particular, the spectral similarity between soil and dry vegetation has been primary concern to correctly appraise the surface conditions during the non-growing seasons in temperature region. This study analyzes the spectral characteristics of the mixture of dry vegetation and soil. The reflectance spectra were obtained from laboratory spectroradiometer measurement and from EO-1 Hyperion image data. The reflectance spectra of several samples having different level of dry vegetation fractions show similar pattern from both lab measurement and hyperspectral image. Shortwave IR wavelengths, in particular at wavelength near $2200 \mathrm{~nm}$, are more sensitive to the fraction of dry vegetation. The reflectance spectra of bare soil could be distinguished from the other surfaces covered by dry vegetation during the leaf-off season.
\end{abstract}

Keywords - dry vegetation, crop residue, spectral reflectance, spectroradiometer, hyperspectral sensing

\section{INTRODUCTION}

In temperate regions where the growing season is relatively short, it is often difficult to accurately assess the surface conditions among soils, croplands, grasslands, and disturbed forests. Crop residue and dry vegetation are spectrally very similar with soils in visible and near infrared wavelengths [1]-[2]. The spectral similarity between soils and dry vegetation has been major obstacle to correctly classify and evaluate various land cover types with multispectral data that had been obtained during the non-growing seasons in temperature region.

Dry vegetation plays an important role to stabilize agricultural, grassland, and forest ecosystems by reducing soil erosion and increasing organic matter [3]. Intensive agriculture, over-grazing and overexploitation of mountainous forest have been great concern in several places of temperate region. In particular, the large-scale conversion of mountainous forest to croplands have been a significant

\author{
Yang-Dam Eo and Yong-Woong Lee \\ Agency for Defense Development \\ P. O. Box 35, Yusung, Daejeon, KOREA
}

impact to degrade the environmental quality and, consequently, to reduce the capability for crop production. Because of the difficulty to obtain cloud free imagery during the summer when the discrimination between bare soil and vegetation can be maximized, there have been very little attempt to monitor the surface conditions of such degraded lands with remote sensor data [4]. The surface conditions of early spring and fall are primarily either bare soil or dry vegetation and, therefore, it is rather difficult to correctly separate between the abandoned croplands (bare soil) and the crop residue coverage after harvest.

Spectral absorption features in shortwave infrared wavelengths have been known to be effective for assessing crop residue from soil by laboratory spectral measurements [5]-[7]. Spectroscopic approaches to separate crop residue from soil can be fundamental information for estimating crop residue using remotely sensed data. The primary objective of this study was to characterize the spectral reflectance of various surface conditions in non-irrigated agriculture lands, grasslands, and disturbed forests during the leaf-off season in temperate region. The reflectance spectra of various surface conditions can be directly related to the accurate classification of land covers using newly developed hyperspectral remote sensor data.

\section{METHODS}

This research is based on a laboratory experiments measuring spectral reflectance of various samples of soil and dry vegetation. Further reflectance spectra on various surface conditions were obtained from EO-1 Hyperion hyperspectral image data.

\section{A. Laborlatory Spectral Measurements}

A laboratory experiment was conducted to measure the reflectance spectra of dry vegetation samples using a portable spectroradiometer. Seven samples of having different level of dry vegetation fraction $(0 \%, 10 \%, 20 \%, 40 \%, 60 \%, 80 \%$, and $100 \%$ ) were prepared within the area corresponding to the field of view (FOV) of the spectroradiometer. Dry vegetation was collected from corn field at approximately 4 months after harvest. For each sample, the exact fraction of dry vegetation 
(corn) was determined from the vertical photographs of portable digital camera.

Reflectance spectra were measured using a portable spectroradiometer (GER 2600), which can measure spectral reflectance over the wavelength region between $350 \mathrm{~nm}$ and $2,500 \mathrm{~nm}$. Reflectance spectra were measured at $2 \mathrm{~m}$ above the sample with a 10 degrees FOV lens. The actual size of the FOV for the spectroradiometer did not exactly correspond to simple trigonometry calculation and it looks an ellipse shape with diameters of $43 \mathrm{~cm}$ and $28 \mathrm{~cm}$. The samples were illuminated by two $500-\mathrm{W}$ halogen lamps positioned $90 \mathrm{~cm}$ over the sample. For each sample, spectral reflectance was measured four times and average reflectance were plotted as a function of wavelength. At each measurement, the spectroradiometer actually provides percent reflectance value for 612 continuous bands over the wavelength from $350 \mathrm{~nm}$ and $2,500 \mathrm{~nm}$.

As an initial approach to detect particular spectral absorption features among seven samples, we applied the continuum removal method [6]. The continuum removal method allows us to compare absorption features from a common baseline. The continuum-removed reflectance is obtained by dividing the original reflectance by the reflectance value on continuum line. The continuum-removed reflectance is equal to 1.0 where the continuum and the original reflectance spectra are the same and less than 1.0 where absorption features occur.

\section{B. Image spectra from Hyperion data}

In addition to the reflectance spectra from laboratory measurements, field reflectance spectra were obtained from EO-1 Hyperion hyperspectral image data. Although EO-1 Hyperion data are known to have relatively poor radiometric quality as compared to airborne imaging spectrometer data, such as the NASA's AVIRIS, they are the only available hyperspectral data over the study area [8]. The Hyperion data over the Kwangju and suburban area in southern part of Korean Peninsula were obtained on November 22, 2002. The original data contain 242 spectral bands, each approximately $10 \mathrm{~nm}$ wide, ranging from 356 to $2,577 \mathrm{~nm}$. After initial radiometric calibration procedure to reduce inherent sensor noises, the data were georeferenced and converted to surface reflectance. The Hyperion data having $30 \mathrm{~m}$ spatial resolution were georeferenced to plane rectangular coordinates using a set of ground control points (GCP) from digital topographic maps.

Atmospheric water-vapor is a key factor in the atmospheric correction of optical remote sensor data. The atmospheric correction of hyperspectral data has a clear advantage over multispectral data since the intensity of atmospheric water-vapor at the time of data acquisition can be directly obtained from a few spectral channels of the data themselves. In this study, we used the ACORN program (AIG, 2002), which was based on the MODTRAN4 radiative transfer code. ACORN used two water absorption channels (940 $\mathrm{nm}$ and $1140 \mathrm{~nm}$ ) in Hyperion data to estimate the amount of water vapor at the time of data acquisition.

To build a meaningful relationship between various surface conditions over vegetative areas and reflectance spectra from hyperspectral data, the ground truth collection must be contemporaneous with the date of image acquisition. However, in this study, the ground truth data were not available at the time of data capture. Using various scales of topographic maps and land cover maps, several points of known surface conditions were selected. Although the exact percent coverage of dry vegetation was not known for each sample site, the surface conditions of the sample plots greatly varied for the leaf-off season except for the coniferous forests. For each sample plot, average reflectance value was obtained from $2 \times 2$ pixels' area $\left(60 \times 60 \mathrm{~m}^{2}\right)$. Of the 242 bands in the full Hyperion dataset, about 70 bands of strong atmospheric waterabsorption and high instrument noises were excluded.

\section{RESULTS AND DISCUSSIONS}

Figure 1 shows the laboratory-measured reflectance spectra of seven samples representing $0 \%$ to $100 \%$ fractions of dry vegetation. Although two primary water absorption bands near 1450 and $1950 \mathrm{~nm}$ are distinct, the reflectance spectra are almost proportional to the percent coverage of dry vegetation. Beside two water absorption bands, the other minor absorption bands are found near 2050 and $2200 \mathrm{~nm}$. In spectroscopic studies, these absorption bands are known to have close relationship with cellulose and lignin, which are the main compounds of dry vegetation [9]. The relatively dark soil $(0 \%$ fraction) has the lowest reflectance and the $100 \%$ fraction sample shows the highest reflectance. The reflectance spectra of other fraction samples are more likely the spectral mixture of these two extreme spectra, in particular at wavelength shorter than $1900 \mathrm{~nm}$. The addition of the dry corn residue over the dark soil background increases the reflectance value. However, such proportional increase of reflectance became reversal at wavelengths near $2200 \mathrm{~nm}$. Adding more dry vegetation decreases the reflectance at these spectral bands, which corresponds to several previous studies [2], [7].

Figure 2 shows the continuum-removed reflectance spectra. The continuum line was set up to connect local maxima of an absorption band and, therefore, is greater than the original reflectance. Once the continuum line is divided by the original reflectance, the resulted reflectance is equal to 1.0 where the continuum and the original reflectance spectra are the same and less than 1.0 at the absorption features. In the continuum-removed spectra, several absorption features are more apparent than in Figure 1. Again, the absorption features are mostly found in shortwave infrared region. Beside of two water absorption bands of 1450 and $1950 \mathrm{~nm}$, we can observe other absorption features in 700,1550 , and $2200 \mathrm{~nm}$. The establishment of a continuum line can vary the outcome 
of continuum-removal analysis. Further refining on the determination of continuum line may provide us better distinction of absorption features to separate different fraction level. Another way of detecting particular spectral features is a simple derivation of original reflectance spectra. In Figure 3 showing the first derivative reflectance spectra, we can also detect several spectral features in which most of them are closely matched with Figure 1 and 2.

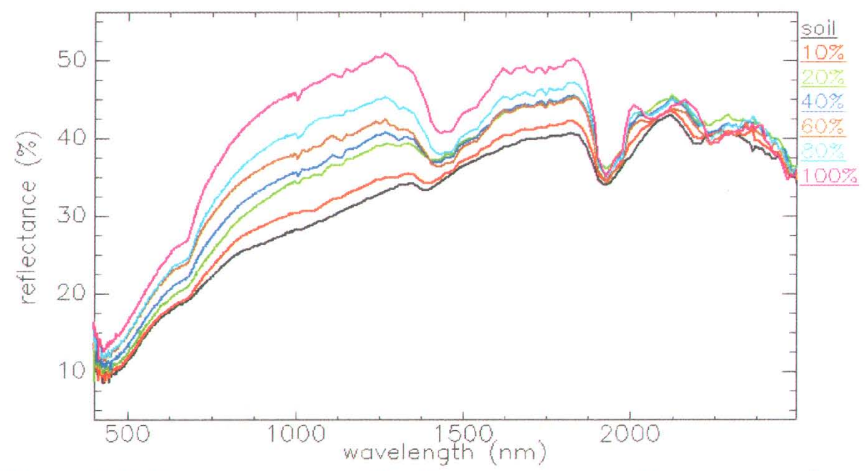

Figure 1. Laboratory measured reflectance spectra of seven samples representing $0 \%$ to $100 \%$ fractions of dry vegetation.

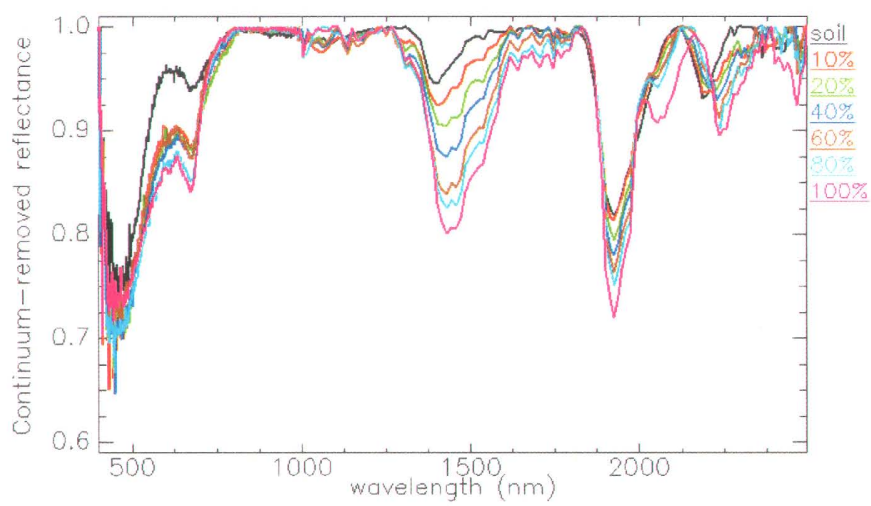

Figure 2. Continuum-removed reflectance spectra of seven samples representing $0 \%$ to $100 \%$ fractions of dry vegetation.

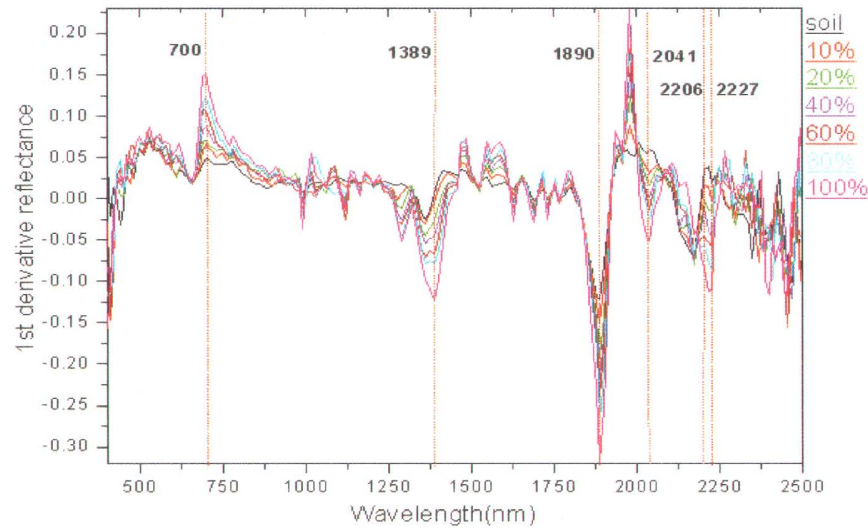

Figure 3. The first derivative of the reflectance spectra of dry vegetation samples of various fractions.
Considering the $30 \mathrm{~m}$ spatial resolution of Hyperion image data, the reflectance spectra obtained from the hyperspectral data have mixed nature of soil, dry vegetation, and other surface materials. Figure 4 shows the reflectance spectra and the continuum-removed spectra of field sample plots having various surface conditions of the leaf-off season on November 22. Except for the coniferous forest, the other field plots were surely covered by dry vegetation. The coniferous pine forest (Pinus rigida and Pinus thunbergii) was very dense canopy closure and might be very little influence of spectral reflectance of dry vegetation. The reflectance curve of the coniferous forest shows a classic form of green vegetation with strong water absorption features at wavelengths near $940,1100,1400$, and $1900 \mathrm{~nm}$. Unlike to the relatively dark soil sample used in the lab measurement, the soil plot was very bright site and assumed no dried vegetation residues.

The other six reflectance spectra were extracted from the sites of rice field, non-irrigated cropland, grassland, and shrub. It is somewhat usual to see the relatively high reflectance of the dry vegetation classes in near-IR and SWIR region. In wavelength longer than $1100 \mathrm{~nm}$, the dry vegetation sites have much higher reflectance than the evergreen forest. Probably, the deciduous oak forest and shrub had the largest amount and fraction of dry vegetation as compared with other classes. However, the other classes of grassland and cropland show the lowest reflectance near $2200 \mathrm{~nm}$ in Figure 4-b. Although the exact amount and fraction of dry vegetation was not known, these sites had different type and fraction level of dry vegetation. In this preliminary analysis of comparing the reflectance spectra, we tried to find particular wavelength bands that might show the maximum separation among these classes.

The continuum-removed reflectance spectra (Figure 4-b) clearly show several absorption features. Excluding the green vegetation of coniferous forest, the predominant spectral absorption features are found in visible $(500-690 \mathrm{~nm})$ and the second shortwave IR $(2050-2400 \mathrm{~nm})$ wavelengths. Because of relatively high level of signal noise of Hyperion data, it is not clear to define specific narrow absorption bands. However, the maximum difference among the dry vegetation classes can be achieved in the second middle IR region. The broad absorption band in visible wavelength, that was not very apparent in the lab spectral measurement, might come from the different type of vegetation and soil background. Spectral characteristics of various surface conditions during the nongrowing season are dependent upon soil type, chemical constituent of dry vegetation, and moisture conditions of soil and vegetation. Without knowing the exact status of the surface condition at the time of the Hyperion data acquisition, it would be premature to make a certain conclusion. Further spectral analysis on the interaction of these factors could provide us better understand of spectral reflectance on dry vegetation. 


\section{CONCLUSIONS}

Due to the problem of obtaining optical remote sensor data during the growing season, it has been rather difficult to assess the surface condition and to correctly classify land cover types over the vegetative area. The spectral characteristics of mixed soil and dry vegetation may provide us to solve such problem. Based on the reflectance spectra obtained from both lab measurement and satellite hyperspectral data on several types of dry vegetation samples, the following conclusions can be made.

- The reflectance spectra of bare soil, which is a typical surface condition abandoned no-longer productive cropland, could be distinguished from the other surfaces covered by dry vegetation. The classification of such abandoned croplands in mountainous area may be greatly dependent upon the spectral variability of background soils.

- Shortwave IR wavelengths, in particular at wavelength near $2200 \mathrm{~nm}$, are more sensitive to the fraction of dry vegetation.

- Similar patterns were found from both lab spectra and image spectra, except for more distinct absorption features at visible wavelength with Hyperion data. Relatively poor radiometric resolution of Hyperion data was problematic to derive noise-free reflectance spectra.

\section{References}

[1] Daughtry, C.S.T., E.R. Hunt Jr., and J.E. McMurtrey III., "Assessing crop residue cover using shortwave infrared reflectance", Remote Sensing of Environment, Vol. 90, pp.126134,2004

[2] Streck, N.A., D. Rundquist, and J. Connot, "Estimating Residual Wheat Dry Matter from Remote Sensing Measurements" Photogrammetric Engineering and Remote Sensing, Vol. 68, No. 11. pp. 1193-1201, Nov. 2002.

[3] Lal, R., J. M. Kimble, R. F. Follett, and C.V. Cole, "The potential of U.S. cropland to sequester carbon and mitigate the greenhouse effect". Boca Raton, FL: Lewis Publishers. 128 pp. 1999.

[4] Lee, K.S., "Vegetation Cover Type Mapping Over The Korean Peninsula Using Multitemporal AVHRR Data", Jour. of Korean Forestry Society, 83(4): 441-449. 1994 (in Korean)

[5] Elvidge, C. D., "Visible and near infrared reflectance characteristics of dry plant materials". International Journal of Remote Sensing, 10, 1775-1795. 1990.

[6] Kokaly, R. F. and R.N. Clark, "Spectroscopic determination of leaf biochemistry using band-depth analysis of absorption features and stepwise multiple linear regression". Remote Sensing of Environment, 67, 267-287, 1999.

[7] Daughtry, C. S. T. "Discriminating crop residues from soil by shortwave infrared reflectance". Agronomy Journal, 93, 125 131. 2001.
[8] Asner G.P. and K.B. Heidebrecht, "Imaging Spectroscopy for Desertification Studies: Comparing AVIRIS and EO-1 Hyperion in Argentina Drylands", IEEE Transactions on Geoscience and Remote Sensing, Vol. 41(6):1283-1296. 2003

[9] Curran, P.J., "Remote sensing of foliar chemistry. Remote Sensing of Environment", Vol. 30, 271-278. 1989.
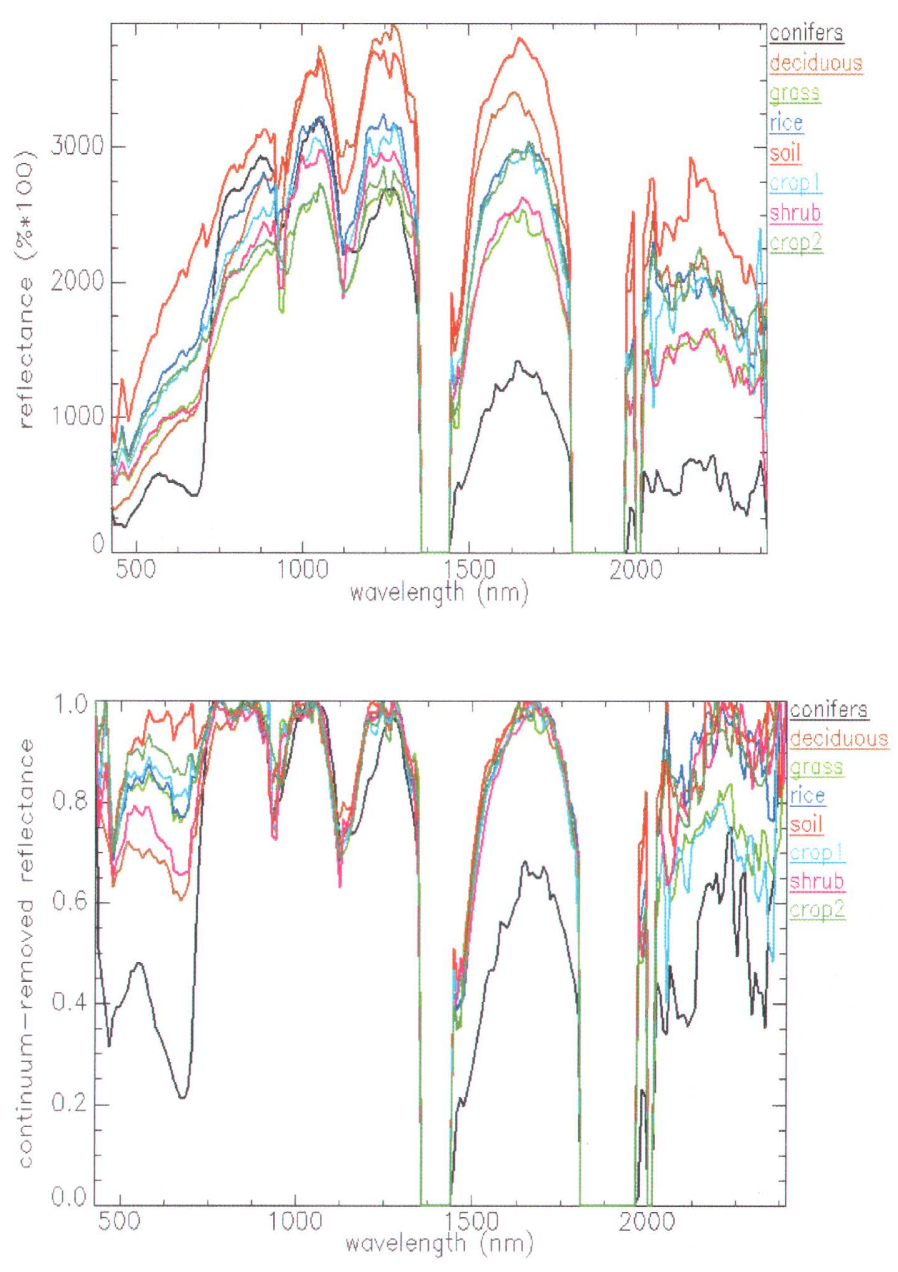

Figure 4. Reflectance spectra of field plots having various surface condition, which were obtained from EO-1 Hyperion data during the leaf-off season: top - percent reflectance, bottom - continuum removed reflectance. 